\title{
La historia económica en el Seminario de Historia Rural Andina
}

\author{
Alejandro Salinas Sánchez \\ asalinass_ac@unmsm.edu.pe \\ Universidad Nacional Mayor de San Marcos \\ Facultad de Ciencias Sociales \\ Instituto Seminario de Historia Rural Andina
}

\begin{abstract}
SUMILLA:
Este artículo analiza el rol del Seminario de Historia Rural Andina y de Pablo Macera en la formulación de los criterios teóricos y metodológicos que guiaron los primeros trabajos de la moderna historia económica peruana de la segunda mitad del siglo XX. Se distinguen tres etapas en el continuo proceso de producción bibliográfica del SHRA (1966-1978, 1979-2000 y 2001-2015) destacando las perspectivas de los investigadores actuantes al interior de cada una de estas en el marco de los debates historiográficos ocurridos durante los últimos cincuenta años.

Palabras-clave: Perú; historiografía; historia económica; Seminario de Historia Rural Andina; Pablo Macera.

\section{The Peruvian economical history and the role of the Seminario de Historia Rural Andina}

\begin{abstract}
:
This article analyses the role of the Seminario de Historia Rural Andina and of Pablo Macera designing methodological and theoretical criteria guiding the first research efforts of modern Peruvian economical history in the second half of the XX Century. Such research has been divided into three phases: 1966-1978; 1979-2000; and 2001-2015. Each phase is marked by specific characteristics of the theoretical orientation of the investigators in the context of the history debates that have occurred in the past five decades.

Keywords: Peru; historiography; economic history; Seminar of Andean Rural History; Pablo Macera.
\end{abstract}

\section{Introducción}

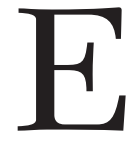

ste artículo analiza el papel cumplido por el Seminario de Historia Rural Andina (SHRA), fundado por Pablo Macera, en la formulación de los criterios teóricos y metodológicos que guiaron los primeros trabajos de la moderna historia económica peruana. En ese contexto, destacaremos el trabajo de asesoramiento recibido por los jóvenes historiadores sanmarquinos en los talleres del SHRA, la apertura de nuevas líneas de investigación y la publicación de textos pioneros en la historiografía económica. Finalmente, se distinguen tres etapas (1966-1978, 1979- 
2000 y 2001-2016) en el continuo proceso de producción bibliográfica del SHRA destacando las perspectivas de los investigadores actuantes al interior de cada una de estas en el marco de los debates historiográficos ocurridos durante los últimos cincuenta años.

\section{Pablo Macera, el Seminario de Historia Rural Andina y los inicios de la Historia Económica Peruana}

Desde los inicios de nuestra vida republicana existió preocupación por analizar la economía nacional, y aunque dicho interés se mantuvo en el transcurso del siglo XIX, careció de impulso para forjar una escuela orgánica de historiadores económicos. Los hacendistas de aquella época dieron especial importancia a la información estadística, porque entendieron que la carencia de esta información impedía diseñar el progreso del país. Ciertamente, las Bases para la estadística del Perú, publicadas entre 1826 y 1827 por El Peruano, constituyen el punto inicial de nuestra literatura económica republicana. Su autor, Andrés Salazar y Muñatones, aplicó una serie de principios estadísticos sobre la información demográfica disponible con el propósito de establecer tendencias en el crecimiento demográfico y ocupación productiva del espacio. ${ }^{1}$ Sin embargo, en las décadas siguientes, los funcionarios públicos fracasaron en su intento de organizar una base de datos actualizada y de carácter nacional, pues la discontinuidad y fragmentación fueron vicios usuales en las matrículas tributarias, censos y registros cívicos producidos hasta fines del siglo XIX. Para corregir ese descuido de la burocracia, el presidente Manuel Pardo encargó a Agustín de la Rosa Toro que, desde el Ministerio de Gobierno, ordenara a los prefectos y subprefectos enviar memorias con información socio-económica de sus provincias. Empero, las pugnas políticas y crisis financiera frustraron la continuidad de este trabajo.

No tuvieron mejor suerte los académicos, pues solo José María Córdova y Urrutia y Manuel Atanasio Fuentes lograron publicar sus trabajos estadísticos sobre Lima en 1839 y 1867, respectivamente. Esta situación cambió en el decenio de 1870, cuando el debate de las cuestiones financieras facilitó la difusión de los textos de José Manuel Osores y Juan Copello y Luis Petriconi. En la posguerra del Pacífico, los estudios privilegiaron el examen de "problemas concretos" en desmedro de las "generalizaciones" y "análisis retrospectivos". ${ }^{2}$ Con todo, Emilio Dancuart y José M. Rodríguez brindaron, a través de sus Anales de la hacienda pública, la compilación de datos más completa sobre nuestras finanzas decimonónicas. Entrado el siglo XX, universitarios e intelectuales mostraron creciente interés por la literatura económica. En ese contexto, César Ugarte y Emilio Romero bosquejaron el panorama histórico de la economía peruana, mientras José Carlos Mariátegui y Víctor Rául Haya de la Torre interpretaron dicho proceso desde la visión marxista y aprista de la historia. Desde entonces y hasta inicios del decenio de 1960 existió incomunicación "entre los altos centros de estudio y los pocos especialistas en historia económica". ${ }^{3}$

Durante los años 1950, Pablo Macera recibió una formación universitaria "deficiente", pues los grandes maestros sanmarquinos, como Julio C. Tello, habían muerto y los cursos de sociología ya no se dictaban. Por ese motivo, realizó su posgrado en Francia donde, abocado a un intenso proceso de reconversión académica, concluyó que la universidad peruana daba entonces a los

\footnotetext{
Salinas 2001: 1-7.

Macera 1977: tomo I, 41

Macera 1977: tomo I, 69 .
} 
historiadores una preparación en métodos y técnicas “absolutamente válida” para 1900. ${ }^{4}$ En 1963, Pablo Macera retornó al país después de concluir sus fructíferos estudios de posgrado. En los años siguientes, en medio del debate político sobre la reforma agraria, organizó tertulias y talleres de investigación para estudiantes de Historia en su propia casa. En dicho cenáculo compartió su preocupación académica por investigar la cuestión rural y el funcionamiento de la hacienda como unidad productiva. Para abordar dichos temas, fundó en marzo de 1966 el SHRA en la Facultad de Letras de la Universidad Nacional Mayor de San Marcos (UNMSM), y emprendió con sus alumnos sanmarquinos la fascinante tarea de redescubrir la historia económica. Hasta entonces, la "literatura económica peruana” carecía de unidad, pues las investigaciones reflejaban una pluralidad de modalidades "heterogéneas y discontinuas". ${ }^{5}$ Sin embargo, a partir de esos años, como resultado de los vínculos establecidos con la historiografía moderna europea, se produjo el resurgimiento del "interés histórico-económico". Los historiadores económicos formados en dicha coyuntura modificaron sus métodos y "puntos de vista” para consagrarse al estudio de los precios, minería, economía agraria, demografía, hacienda pública y mercados internos de la época colonial. ${ }^{6}$

La renovación metodológica fue entonces uno de los ejes principales de la labor historiográfica de Pablo Macera. En esa tarea, según Manuel Burga, fue notoria la influencia de la historiografía francesa. De allí su interés por la "larga duración", precios y salarios, y sus reiteradas menciones a las obras de Marc Bloch, Lucien Fevbre, François Simiand, Ernst Labrousse, Henri Pirenne, Paul Mantoux y Pierre Vilar. ${ }^{7}$ Como hemos indicado, la reforma agraria y el creciente interés de los historiadores latinoamericanos por analizar la evolución histórica de la hacienda generó "una receptividad general en el país en cuanto a los problemas del campo" y el SHRA se convirtió en "un canal institucional y académico" para el desarrollo de las investigaciones rurales. ${ }^{8}$ De ese modo, el SHRA “influyó positivamente en la formación de los mejores historiadores de las últimas décadas". ${ }^{9}$ El proyecto de Pablo Macera marcó además un hito en la renovación de la historia económica peruana, porque basado en el estudio de nuevos fondos documentales estableció técnicas y métodos estadísticos para organizar series de precios y salarios "según el modelo de Mitchel, Deane y Marczewsky". ${ }^{10}$ Para esbozar esta propuesta, Pablo Macera consultó los trabajos Introduction à l'histoire quantitative (1965) de Jean Marczewski y Abstract of british historical statistics (1962) de B.R. Mitchel y Phyllis Deane.

En simultáneo, inició el trabajo pionero de capacitar estudiantes de ciencias sociales de la UNMSM en la clasificación y organización de los datos obtenidos de fuentes primarias (Archivo General de la Nación, Centro de Documentación Agraria, Archivo del Ministerio de Fomento, etc.) en tablas y cuadros, que permitieran conocer el particular curso histórico de la economía peruana, precisando sus momentos de auge o crisis coyunturales, así como la participación de los individuos (empresarios) en el manejo de las unidades productivas. Sin duda, este "entrenamiento académico" en el SHRA ${ }^{11}$ proveyó a una generación del know how para reconstruir y analizar la evolución histórica de nuestra producción (minera, comercial y agropecuaria) y demografía colonial y republicana. Manuel Burga, destacado integrante del grupo estudiantil fundacional del

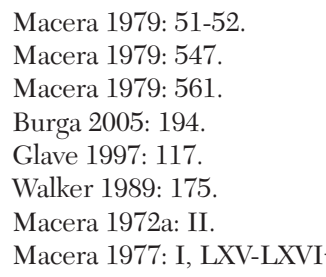


seminario, recuerda que este surgió como un esfuerzo por repetir las tertulias organizadas por Raúl Porras, pero bajo otras perspectivas, pues Macera trajo de Francia "las ideas, los libros y las nuevas amistades", que fueron fundamentales en la forja de "una moderna historia crítica, nacional, andina y peruana”. En ese ambiente, los estudiantes fortalecieron vocaciones, actualizaron conocimientos y rompieron con la Tradición anterior para acercarse hacia "una dimensión nueva de la historia económica" mediante el estudio de las temporalidades jesuitas y aplicando el principio de que las cifras debían apreciarse como "expresiones cualitativas de una historia social" en vez de "magnitudes cuantitativas". ${ }^{12}$ Al respecto, podemos diferenciar tres fases (1966-1978, 1979-2000 y 2001-2015) en el desarrollo de las investigaciones económicas del SHRA.

\section{Primera fase: los inicios de los estudios cuantitativos (1966-1978)}

Entre 1966 y 1978, Pablo Macera sentó las bases del trabajo multidisciplinario del SHRA. A inicios del decenio de 1960 era evidente el estancamiento en que estaban sumidas la Historia y las ciencias sociales, pues se había abandonado "la reflexión científica sobre la formación social peruana" desarrollada por José Carlos Mariátegui durante la década de $1920 .{ }^{13}$ La historiografía tradicional de entonces, caracterizada por ser "principalmente narrativa y poco moderna", carecía de metodología para analizar los problemas sociales y económicos del país en un contexto de fermento ideológico influenciado por la literatura marxista y la retórica revolucionaria desplegada como sustento de la Reforma Agraria. ${ }^{14}$ En 1963, culminado sus estudios de posgrado en Francia, Pablo Macera regresó al Perú con la ambiciosa idea de renovar la historia económica con los conceptos y métodos aprendidos en Europa. Dos fueron los proyectos que emprendió entonces: el estudio de la hacienda colonial y la elaboración de series estadísticas sobre demografía, precios y tributos republicanos, tales como las que habían efectuado algunos historiadores franceses de la escuela de los Annales. Esta propuesta de modernización historiográfica no estaba pensada en términos únicamente nacionales, sino que comprendería toda el área sudamericana. El objetivo de Pablo Macera consistía en construir una base de datos económicos de dimensión continental. Ciertamente, esa tarea solo podía efectuarse de manera colectiva.

Por ese motivo, desde la cátedra universitaria, Pablo Macera convocó grupos de estudiantes a su casa de la calle José Díaz (Lince, Lima) para compartir tertulias sobre la necesidad de actualizar conocimientos y formar talleres de investigación. El SHRA le dio cobertura institucional a esas labores académicas y -bajo la dirección de Pablo Macera- asumió la responsabilidad de subsanar las falencias de la historiografía económica peruana mediante cuatro acciones: edición de textos clásicos de literatura económica, visitas guiadas a los archivos, entrenamiento en la clasificación y análisis de los fondos documentales y publicación de la información seleccionada precedida por estudios introductorios. De esa manera, los estudiantes reunidos en el SHRA comenzaron a aplicar nuevos métodos y técnicas de investigación durante la consulta de los papeles de las Temporalidades jesuitas conservadas en el Archivo de la Nación. Todos ellos trabajaron bajo el compromiso intelectual de encontrar nuevas explicaciones para hechos considerados "naturales" por historiadores tradicionales que escribían una interpretación de la historia peruana compatible con sus intereses. ${ }^{15}$

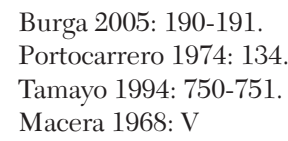


Apenas fundado el SHRA, Pablo Macera, apoyado por los entonces estudiantes Wilson Reátegui, Manuel Burga, Lorenzo Huertas, Leonidas Montalvo, Luis Villegas, Margot Ventura, César Cerdán, Alberto Colunga, Marina Matusita, Clelia Pacheco, Andrés Huguet, Angélica Aranguren, Wilma Derpich, Marlene Polo, Ester Pozo y Trinidad Ríos, publicó las Instrucciones para el manejo de las haciendas jesuitas del Perú, siglos XVII y XVIII (1966) en el número 2 de la revista Nueva Corónica de la Facultad de Letras de la UNMSM. Este trabajo inauguró la prolífica labor editorial del SHRA. Al año siguiente, una reseña aparecida en la revista Historia de la Universidad Católica de Chile calificó este texto como un "valioso aporte" historiográfico, porque presentaba "documentos pertinentes" y cuadros sinópticos útiles para el estudio de las "formas económicas" implantadas por los jesuitas en los trabajos de sus haciendas. ${ }^{16}$ Por su importancia, esta publicación del SHRA ha sido citada reiteradas veces en los estudios sobre hacienda colonial realizados en diversos países latinoamericanos. Podemos encontrar referencias sobre las Instrucciones en los trabajos de Armold Bauer (1986), Germán Colmenares (1998), Herman Konrad (1989) y Magnus Morner (1979).

Macera destacó entonces el trabajo en equipo y atribuyó la autoría de esta publicación al SHRA, que iniciaba así una serie dedicada al estudio de la agricultura peruana del siglo XVIII. Estas Instrucciones apelando a información contenida en las secciones de Cuentas y Títulos de hacienda del fondo de Temporalidades del Archivo Nacional del Perú, revelaron el "comportamiento económico de los jesuitas" y ofrecieron "riquísima y variada información” sobre técnicas de cultivo, sistemas de trabajo, régimen de salarios, etc. ${ }^{17}$ Este texto se convirtió rápidamente en un clásico de la historiografía latinoamericana y referente obligatorio en todos los estudios sobre la administración económica de las haciendas jesuitas coloniales. En los años siguientes, el SHRA reafirmó su compromiso con el estudio de la sociedad agraria colonial y el problema de la tierra desde una perspectiva crítica.

Otros centros de investigación, como el Instituto de Estudios Peruanos (IEP), también dedicaron sus primeros textos al estudio de la hacienda y campesinado, apoyando sus conclusiones en bibliografía coetánea, crónicas coloniales y trabajo de campo. Los textos La evolución y la situación de las haciendas en la región de Huancavelica, ${ }^{18}$ La Hacienda en el Perú ${ }^{19}$ y Haciendas y Comunidades tradicionales en un contexto de movilización campesin $a^{20}$ reflejaron el creciente interés de la Historia y otras ciencias sociales por los asuntos agrarios. Ciertamente, desde su fundación en 1964, el IEP estableció como una de sus prioridades el análisis de los “cambios rurales", porque estos eran una condición necesaria para modificar "las estructuras de la dominación interna”. Entre 1967-1968, el IEP publicó tres trabajos referidos a haciendas y comunidades, y asesoró diez tesis universitarias sobre estas mismas cuestiones. ${ }^{21}$

Durante 1966 y 1967, el SHRA siguió recopilando materiales sobre la economía rural andina. Los estudiantes Angélica Aranguren, Rosa Boccolini, Rosario Jiménez, Mauro Escobar y David Motta revisaron libros de gastos y padrones tributarios con el objeto de publicar investigaciones sobre los precios de Lima, Arequipa y Cuzco (1670-1800) y la tenencia de la tierra (1720-1854), pero el SHRA carecía de recursos para costear la impresión de sus textos y recurrió al mimeógrafo a fin de difundirlos inmediatamente. Esa "modestia gráfica” no menoscabó la importancia del

16 Aranguiz 1967: 391

17 Macera 1966: 5.

18 Henri Favre: 1966.

19 Henri Favre, Claude Collin-Delevaud y José Matos Mar: 1967.

20 Julio Cotler, 1968.

21 IEP 1968: 4-5. 
SHRA, pues profesores extranjeros, como John Fisher y Noble David Cook, aceptaron publicar sus estudios bajo este formato. En 1968, circuló Mapas coloniales de haciendas cuzqueñas, que reprodujo "planos agrarios" de dicha región efectuados por Ramón de Arechaga en el siglo XVIII, y entregó un balance acerca del debate historiográfico en torno a la hacienda e información valiosa sobre salarios, mano de obra, estructura y Funcionamiento de las haciendas cuzqueñas dieciochescas. En este trabajo además de los estudiantes mencionados, participaron Wilfredo Kapsoli, Wilson Reátegui, Andrés Huguet, Clelia Pacheco y Marina Matusita.

A inicios del decenio de 1970, el escenario historiográfico estuvo influenciado por el surgimiento de la Nueva Historia y la denominada teoría de la dependencia ${ }^{22}$. En la década citada, algunos estudiantes de Historia que habían integrado el SHRA, como Manuel Burga y Wilfredo Kapsoli, animados de "nuevas perspectivas y agendas" impulsaron el movimiento de la Nueva Historia, que emergía como una respuesta a la coyuntura de crisis política y cambio social imperante durante esta década. ${ }^{23}$ Estos y otros historiadores de la generación del 68 escuchaban a Pablo Macera, porque en su discurso había “un esfuerzo por pensar desde una tradición histórica y también por la carga moral de sus interpretaciones”. ${ }^{24}$ En este contexto se produce el repliegue de la historiografía tradicional, mientras surgían los nuevos historiadores deseosos de escribir la versión marxista de la historia peruana. Según Carlos Aguirre, la "cultura política de confrontación”, surgida a fines del decenio de 1960, se consolidó entre los intelectuales combinado el trabajo académico con expresiones de clasismo militante. ${ }^{25} \mathrm{Al}$ respecto, los textos de Pablo Macera publicados por el SHRA entre 1968 y 1972 recogieron sus reflexiones sobre el papel del historiador en el proceso histórico nacional. Posteriormente, en sus Trabajos de Historia, publicados en 1977 por el Instituto Nacional de Cultura, expuso con mayor amplitud sus ideas sobre teoría y metodología de la Historia.

En este ambiente, las investigaciones sobre historia económica fueron influidas por la teoría de la dependencia y centraron su interés en "desmontar los mecanismos de extracción de excedentes y de condicionamiento ejercidos sobre el espacio económico peruano". ${ }^{26}$ Los trabajos de Ernesto Yepes (Perú 1820-1920: Un siglo de desarrollo capitalista, 1972) y Heraclio Bonilla (Guano y burguesía en el Perú, 1974; Gran Bretaña y el Perú. Informes de los cónsules británicos, 1826-1900, 1975) publicados por el IEP, desarrollaron estas preocupaciones de la historiografía dependentista por precisar las causas del atraso del país. Asimismo, no podemos dejar de mencionar los trabajos de Shane Hunt sobre exportaciones desde 1830, el impacto del guano y la evolución de los salarios reales hasta mediados del siglo XX, con los cuales construyó "una manera peculiar de explicar el crecimiento económico de largo plazo en el Perú". ${ }^{27}$ Hunt estuvo fuertemente influenciado por la cliometría, y la nueva perspectiva sobre la dependencia sostenida por Thorp y Bertram, quienes estudiaron la "nueva dependencia", a partir de la mayor presencia de capital extranjero en la economía peruana desde finales del siglo XIX. ${ }^{28}$ En medio de estas tendencias, el SHRA impulsó la edición de estadísticas históricas (mineras y agrícolas) y demográficas, fundamentales para tener una visión integral del proceso económico durante la Colonia y posterior desarrollo de la república peruana. En paralelo con estas investigaciones se

22 Para evaluar el impacto de la teoría dependentista sobre la historiografía peruana pueden consultarse los textos de Francisco
Quiroz 1995, y Carlos Contreras 2003.
23 Drinot 2008: 236.
24 Flores Galindo 1987: 108.
25 Aguirre (ed.), 2013: 310.
26 Flores Galindo 1988: 66.
27 Glave 2011: 2-3.
28 Portocarrero 1982: 215. 
organizó la Biblioteca Peruana de Historia Económica, que puso al alcance de los historiadores varios textos importantes para conocer el pensamiento económico nacional entre fines del siglo XVIII e inicios del siglo XX. Durante esta época, Pablo Macera utilizó terminología marxista (modo de producción, formación económico-social, etc.) y planteó el concepto de feudalismo colonial para referirse a la sociedad peruana dominada internamente por relaciones feudales, pero sometida externamente por el capitalismo mundial.

En opinión de Pablo Macera, el SHRA tuvo el mérito de haber sido el primero "en organizar investigaciones históricas sobre la sociedad rural peruana y haber dado oportunidad a gente de todas las clases sociales y tendencias para que recibieran entrenamiento académico". ${ }^{29}$ Sin duda, el SHRA surgió en un contexto de cambio cultural determinado por tres factores: decadencia de la historiografía conservadora, historización de las ciencias sociales e influencia del marxismo ${ }^{30}$. En este escenario, Pablo Macera se convirtió en uno de los principales impulsores del desarrollo de la “idea crítica del Perú” e influyó decisivamente en la formación de varios historiadores de la generación de $1968 .{ }^{31}$ Sin duda, para fundamentar esta posición cuestionadora de la historia nacional se requería de evidencia empírica obtenida de las fuentes primarias. A juicio de Macera, el historiador económico debía conjugar las "interpretaciones" con las sencillas tareas de recopilación bibliográfica y documental. Como resultado de este enfoque metodológico, el SHRA asumió el trabajo pionero de reconstruir las estadísticas históricas de la producción (minera y agropecuaria) y demografía en el territorio nacional. Como precisa Ernesto Yepes, en dicha tarea Pablo Macera puso en práctica su sólida formación profesional, mente ágil y pluma incisiva. Por ese motivo, fue probablemente el historiador "que más influencia ha ejercido sobre los jóvenes estudiosos que a partir de la década del sesenta irrumpen desde diversas disciplinas en el razonamiento histórico peruano". ${ }^{32}$ Durante esta época, varios investigadores extranjeros (J. Fisher, D. Noble Cook) compartieron ese interés por el análisis riguroso de las cifras para establecer tendencias estadísticas en el curso del proceso económico. Gracias al SHRA y la cátedra de Historia Económica de la Facultad de Letras de la Universidad San Marcos, estos investigadores extranjeros enseñaron y transfirieron tecnología a los estudiantes peruanos. ${ }^{33}$

Estas ideas marxistas y dependentistas pueden percibirse en varios textos del SHRA publicados en la década de 1970. En primer lugar, Pablo Macera puso especial interés en el sistema de plantaciones azucareras como espacios rurales dependientes donde se articulan el modo de producción capitalista con formas laborales precapitalistas. ${ }^{34}$ En simultáneo, Lorenzo Huertas presentó la plantación azucarera de Cayaltí como una expresión de capitalismo feudalizado sostenido por la explotación de la clase proletaria agrícola. ${ }^{35}$ Los sociólogos Clemente Soto, Arturo Urbano y Zenón Vargas, a partir del estudio del empobrecimiento de los peones agrícolas del complejo agroindustrial de Paramonga, sostuvieron la necesidad de aplicar el "método dialéctico" para penetrar la esencia de los fenómenos y concluyeron que la "ley de acumulación capitalista” producía la depauperación de la clase obrera. ${ }^{36} \mathrm{~A}$ su vez, Honorio Pinto estaba convencido que la dependencia era "el instrumento teórico más apropiado" para explicar la crisis generada por la exportación de

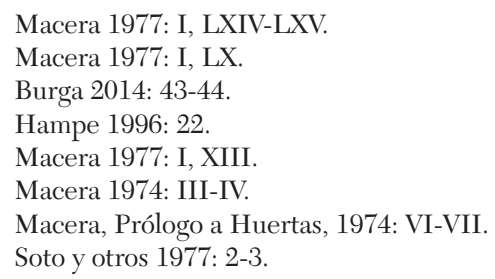


materias primas mineras y agropecuarias, pues dicha actividad era incapaz de generar una estructura productiva nacional. ${ }^{37}$ Debemos mencionar además la propuesta de Javier Tantaleán, destinada a construir una teoría marxista de la historia económica, cuyos principios expresarían "leyes a partir de la observación de lo real". 38

No resulta extraño este predominio del enfoque marxista en las publicaciones del SHRA del decenio de 1970, pues este también orientó los trabajos de la mayoría de intelectuales de esta época. Algunos, como Anibal Quijano, Sinesio López o Rodrigo Montoya, editaron textos sobre imperialismo, oligarquía y capitalismo en el Perú. Otros, como Wilfredo Kapsoli, Antonio Rengifo y Manuel Valladares, fundaron la revista Campesino y se ocuparon del carácter clasista de la movilización del campesinado. En ese sentido, Heraclio Bonilla en un balance realizado en 1980 señaló los logros alcanzados por la investigación histórica en la década precedente y advirtió que la preferencia por el marxismo “depurado de sus interpretaciones dogmáticas", exigió a los historiadores abocarse al estudio de los resortes fundamentales del cambio social. ${ }^{39}$ Este balance ofreció un minucioso registro de los textos nacionales y extranjeros publicados sobre las diversas especialidades históricas, pero omitió mencionar las del SHRA, que planteaban una "perspectiva diferente" para abordar "la organización social y los conflictos en el mundo rural" . ${ }^{40}$ Tampoco destacó la importancia de la "producción intelectual" de Pablo Macera, que terminó "confundido dentro de una pequeña constelación de brillantes historiadores". ${ }^{41}$

En este escenario, después de lamentar el "bajo nivel” de la historiografía económica, Macera culpó de esta situación al “monopolio expropiatorio de la información básica” ejercido por quienes pretendían "sobrevalorar sus propias investigaciones". ${ }^{42}$ Para remediar ese problema creó en dicho año el Centro Peruano de Historia Económica, cuyo propósito fue compilar estadísticas económicas y estimular la lectura y debate de textos inéditos o "difíciles de consultar" escritos por hacendistas actuantes entre fines del siglo XVIII e inicios del siglo XX. De ese modo, surgió la Biblioteca Peruana de Historia Económica, cuya primera publicación reprodujo los Apuntes para la Historia Económica del Perú (1882) de Luis Esteves, ensayo que sin alardear erudición contenía "enjuiciamientos y proyectos de solución” de índole hacendaria. Poco después, aparecieron los Estudios sobre la independencia económica del Perú (1876) de Juan Copello y Luis Petriconi, que propusieron el fomento de la industria nacional como único medio para salvar al país de la crisis financiera. En el prólogo de este clásico, Jorge Basadre elogió los esfuerzos de Pablo Macera por reeditar esta obra olvidada y construir "un nuevo planteamiento de nuestra historia" ${ }^{43}$

Con la difusión de esas obras, el SHRA quiso despertar curiosidades en torno a las propuestas de desarrollo económico del siglo XIX. Por esa razón, esta labor editorial continuó en 1972 con la publicación del Ensayo económico-político sobre el porvenir de la industria algodonera fabril del Perú (1849) de Norberto Casanova, de indispensable lectura para quienes desean hacer la historia de la industria y el trabajo fabril, a pesar de constituir el testimonio del fracaso industrialista peruano. ${ }^{44}$ A su vez, El problema industrial en el valle de Chicama (1921) de Lauro Curletti, y el Informe

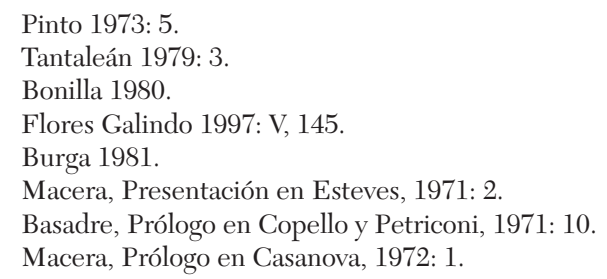


que sobre las huelgas del norte presenta al Gobierno su comisionado don Felipe de Osma (1912) resumieron la perspectiva oficial sobre la industrialización agraria y la explotación de la mano de obra en los valles liberteños. Esta colección de clásicos incluyó en 1974 la Idea sucinta del comercio en el Perú de José Ignacio Lequanda, notable por sus datos cuantitativos del último cuarto del siglo XVIII, y dos folletos del agrónomo francés Jean Martinet titulados Carestía de víveres en Lima, 1875 y La agricultura en el Perú (1877), que contienen interesantes reflexiones sobre las causas de la crisis agrícola y alimentaria que afectó al Perú en el decenio de 1870 e incluyen propuestas para modernizar la producción y distribución de los alimentos.

Por estos años, el Centro Peruano de Historia Económica del SHRA recopiló, analizó y publicó trabajos dentro del Programa de Estadísticas Históricas del Perú. Para este propósito, Pablo Macera organizó un grupo de estudiantes integrado por Alvaro Goicochea, Francisco Merino, David Motta, Mercedes Rosales, Rolando Vilchez y Honorio Pinto, este último asumió la responsabilidad de organizar las estadísticas mineras y agrícolas obtenidas de los boletines, informes y anuarios del Ministerio de Fomento, la Dirección de Minas y el Cuerpo de ingenieros de minas. Macera quiso entonces proveer de "material empírico" a historiadores y economistas, que hasta entonces basaban sus estudios en las cifras consignadas por Dancuart y Rodríguez en los Anales, y otras provenientes de "extractos estadísticos oficiales", aun cuando muchas de estas contenían serios errores. En ese contexto, el SHRA destacó la necesidad de efectuar "tareas sencillas e instrumentales" para dotar a la historia económica de fuentes con que sustentar las hipótesis, técnicas y métodos nuevos e impulsar al mismo tiempo "a largo plazo" una recopilación de series histórico-estadísticas, tales como las que habían realizado en Colombia los historiadores Miguel Urrutia y Mario Arrubla. En 1970, ellos publicaron su Compendio de estadísticas históricas de Colombia, que contenía censos y estadísticas sobre salarios reales y precios desde mediados del siglo XIX.

La consolidación de este proyecto permitiría a historiadores y economistas transitar "de la imaginación al pensamiento crítico suficientemente informado". ${ }^{45}$ Los dos primeros textos de esta serie, publicados en 1972 con los títulos de Estadisticas históricas del Perú: Sector minero (precios) y Estadísticas históricas del Perú: Sector minero (volumen y valor), reunieron datos seriados sobre producción y exportación de minerales (cobre, oro, plata, plomo, zinc) durante los siglos XIX y XX. En simultáneo, Pablo Macera, editó los cuatro tomos de Tierra y Población siglos XVIII-XIX, que recogen la información más completa sobre demografía y tributación colonial y republicana entre 1785-1853, así como instrucciones dadas a visitadores y autoridades fiscales decimonónicas. Todo ese material había sido ubicado y consultado por Macera entre 1965 y 1967, tomándolo del Archivo Nacional del Perú, el Archivo Histórico del Ministerio de Hacienda y la Biblioteca Nacional. Gracias al trabajo colectivo del SHRA se clasificaron estos datos dispersos en 285 cuadros estadísticos. Este "apoyo documental” debía circular como "bien común” entre todos los investigadores para fomentar el debate tan necesario en la historiografía económica de esa época. ${ }^{46}$

Durante 1972, la cuestión rural fue tratada por David Motta y Honorio Pinto. El primero revisó los volúmenes departamentales y el resumen general del censo de 1940, para publicar Población rural en haciendas del Perú, 1940, donde presentó cinco tipos de cuadros estadísticos: a) población de las haciendas, b) población de las estancias, fincas y chacras, c) unidades mayores y menores de mil habitantes, d) población total urbana y rural, y e) comparativo de la población rural departamental respecto del resumen general. Motta advirtió, sin embargo, que los diversos términos (fincas, estancias, etc.) empleados en este censo confundían los resultados. Por su parte, Ho-

45 Macera 1972b: 1

46 Macera 1972c: 4. 
norio Pinto editó El primer censo agropecuario del Perú, 1929, ordenando las “cifras individuales y totales" en cuadros para mostrar el estado de los cultivos en cada departamento según porcentajes "cuidadosamente obtenidos" ${ }^{47}$ En 1973, Pinto preparó otros dos textos denominados Estadísticas históricas del Perú, sector agrícola (Azúcar) y Un sector exportador dependiente: La minería metálica en el Perú 1945-1970. El primero reúne varios cuadros estadísticos sobre producción azucarera en el Perú (1873-1945) y el mundo (1560-1945) e incluye además datos sobre volúmenes de exportación, número de trabajadores y salarios de haciendas limeñas y trujillanas. Para este ensayo fueron revisados materiales de los ministerios de Fomento y Hacienda, anuarios estadísticos y memorias de la Sociedad Nacional Agraria. El segundo utilizó documentos de los bancos Central de Reserva, Industrial y Minero, y de los ministerios de Fomento, Hacienda, Economía y Finanzas y Energía y Minas, para analizar, desde la óptica dependentista, el crecimiento del sector minero subordinado "al poder exterior" y sus negativas consecuencias sobre el desarrollo nacional. ${ }^{48}$

Asimismo, los papeles del archivo de la familia Aspíllaga conservados por el Centro de Documentación Agraria posibilitaron a Pablo Macera escribir Cayalti 1875-1920: Organización del trabajo en una hacienda azucarera del Perú (1973) y Palto. Hacendados y yanaconas del algodonal peruano. Documentos, 1877-1943 (1976). El primero revela aquellos factores (costos, salarios, técnicas, formas laborales) que condicionaron la explotación cañavelera de la hacienda Cayaltí (Lambayeque). A su vez, el segundo detalla la organización laboral y diversos elementos relacionados con la productividad de los algodonales de Palto (Ica). Ambas publicaciones resultan indispensables para comprender cómo resurgieron los cultivos de exportación en la posguerra del Pacífico. En cambio, el enfoque de la estructura productiva azucarera anterior a dicho evento bélico podemos hallarlo en Las plantaciones azucareras en el Perú, 1821-1875 (1974), texto considerado por Manuel Burga como "el estudio global más importante" sobre la agricultura costeña decimonónica, pues plantea:

... preguntas sorprendentemente lúcidas y una serie de análisis rápidos, inteligentes, a veces inconclusos y aparentemente caóticos, sobre las bases que posibilitaron el notable desarrollo de la agricultura azucarera en la segunda mitad del siglo XIX. ${ }^{49}$

Debemos ocuparnos ahora de dos textos de suma importancia aparecidos en 1975: la Tasa de la visita general de Francisco de Toledo de Noble David Cook y la Matrícula de los mineros del Perú, 1790 de John Fisher. El primer documento, procedente del Archivo General de Indias de Sevilla, registró y clasificó a los contribuyentes de los repartimientos de indios de La Paz, Cuzco, Arequipa, La Plata y Guamanga entre 1570 y 1575, y contiene también cifras comparativas de la recaudación durante el período incaico respecto del colonial. Adjuntó además los estudios de Alejandro Málaga y Thérese Bouysse-Casagne, que utilizaron la visita de Toledo para analizar la economía de Arequipa y la distribución étnica en Charcas a fines del siglo XVI, respectivamente. Por su parte, Fisher reprodujo otro documento del citado archivo hispano, que agrupa varios informes remitidos al Tribunal de Minería desde Arequipa, Lima, Cuzco, Huancavelica, Tarma, Trujillo y Huamanga, con los nombres de los mineros y sus propiedades. La información proporcionada por estos funcionarios coloniales refleja el estado de la minería a fines del siglo XVIII, aquejada por la escasez de capitales y reducida dimensión de las minas. Esta publicación del SHRA fue incluida en la Bibliografía minera iberoamericana,

47 Macera, Presentación a Pinto 1972: VI.

48 Pinto 1973: 5.

49 Burga 1978: 11. 
1833-1992, preparada por el Instituto Tecnológico Geominero de España. ${ }^{50}$

El SHRA hizo además otro aporte fundamental a la historiografía económica con los textos Precios en Arequipa 1627-1767 y Precios en Lima 1667-1738, elaborados en 1975 por Pablo Macera con Rosa Boccolini y Rosario Jiménez, respectivamente. Esta "solitaria publicación” rompió "un prolongado silencio en materia de historia de precios". ${ }^{11}$ Según Macera, su interés por los precios comenzó en Francia, durante los estudios de posgrado, realizados a inicios del decenio de 1960, cuando escuchó las “magistrales disertaciones" de Fernand Braudel y Pierre Vilar, además de la influencia ejercida por las lecturas de François Simiand, Ernest Labrousse y Gastón Imbert. Como en otras investigaciones, las principales fuentes consultadas por Macera provinieron de los documentos jesuitas coloniales. En este caso, Rosario Jiménez y Rosa Boccolini recibieron "un conjunto de Libros de Cuentas correspondientes a Lima y Arequipa”. La recolección de precios tardó dos años (1963-1965), pero sus resultados fueron publicados recién hacia 1975. Ambos textos incluyeron "cuadros de frecuencias" que facilitaban medir la confiabilidad de las fuentes. ${ }^{52}$ Posteriormente, en el libro Los precios del Perú, siglos XVI-XIX, editado por el Banco Central de Reserva del Perú, Macera detalló los “modelos de trabajo" empleados en la ubicación de fuentes y clasificación de precios en varios formatos (general, mensual, estacional, producto por año. ${ }^{53}$

En 1977, el texto Estadísticas históricas del Perú. Sector Agrícola. Algodón, efectuado por Honorio Pinto con documentos seleccionados del Archivo del Ministerio de Fomento, presentó cifras acerca de la producción, exportación, cantidad de personal y remuneraciones corrientes en la industria algodonera, asentada principalmente en Piura, Ica y Lima durante la primera mitad del siglo XX. A su vez, Ocupaciones en el Perú, 1876, escrito en coautoría por Honorio Pinto y Álvaro Goicochea, trazó el mapa laboral del país con datos extraídos del censo levantado en dicho año. Los autores definieron diez categorías al interior de la población económicamente activa (PEA) y precisaron su distribución por departamentos. Estos trabajos se complementan con los dos tomos de Agricultura en el Perú. Siglo XX. Documentos (1977), compilación de valiosos informes técnicos y estadísticos sobre producción agropecuaria en Trujillo, Lima, Nepeña, Alto Marañón, Cajamarca y Pisco. Estos documentos recogen la preocupación del Estado por el fomento de dicha actividad tan ligada al bienestar económico de los consumidores. Durante esos años, la investigación desplegada por Macera en el SHRA se caracterizó "por una talentosa combinación de sentido económico común y destreza en el juicio historiográfico y manejo del lenguaje”. ${ }^{54}$

En esta primera fase del trabajo historiográfico del SHRA, aunque predominó la publicación de investigaciones estadísticas también circularon cinco estudios sobre agricultura andina. Sistemas económicos andinos (1973) de César Fonseca Martel examinó la persistencia de la economía familiar de subsistencia basada en el control vertical de los pisos ecológicos, y en el contexto de transición de "una economía tradicional a una economía de mercado en las comunidades campesinas”. ${ }^{55}$ En 1974, Lorenzo Huertas provisto de 283 papeles del Centro de Documentación Agraria y de varias bibliotecas, notarías y periódicos lambayecanos editó Capital burocrático y lucha de clases en el sector agrario. Lambayeque, Perú, 1920-1950. Según Pablo Macera, este libro dentro de la óptica marxista, tiene el mérito de mostrar "de cerca" las relaciones entre una planta-

López de Azcona y otros 1992: 105

Trelles 1986: 21 .

Macera 1992: I, XIII-XIV.

Macera 1992: I, XXIX-XL.

Contreras 2002: 185.

Fonseca 1973: 4. 
ción concreta (Cayaltí) y el proceso político y social peruano "entre las dos guerras mundiales". ${ }^{56}$ De igual forma, El problema agrario en el departamento de La Libertad (1976), reproducción de la tesis universitaria escrita en 1932 por Pablo Carbone, describió "con exactitud” cómo la economía trujillana fue impactada por la agricultura de exportación desde 1914, rompiendo la antigua integración de la hacienda con los "productores de menor cuantía" y otros sectores económicos. ${ }^{57}$

Además de estas cuestiones agrarias, el SHRA abordó también problemas coyunturales. En 1974 y 1975, Pablo Macera publicó dos selecciones documentales tituladas La crisis de 1929 y las economías de Chile y el Perú (Documentos publicados) e Historia económica peruana (Documentos), respectivamente. La primera reproduce un informe conservado en el fondo Cayaltí del Centro de Documentación Agraria, que recoge el parecer de la comisión comercial enviada a Chile en 1932 por cuatro gremios empresariales (Sociedad Agraria, Cámara de Comercio de Lima, Sociedad Nacional de Industrias y Asociación de Ganaderos del Perú) acerca del impacto del crack de 1929 en las relaciones comerciales peruano-chilenas y los mecanismos factibles de aplicarse para reactivar los intercambios en beneficio de las industrias nacionales. La segunda compila informes agrarios producidos entre 1571 y 1914, que han sido tomados del Archivo Nacional del Perú, la Biblioteca Nacional y de periódicos o colecciones particulares. Todos están referidos a técnicas agrícolas, distribución de aguas y regímenes laborales imperantes en las haciendas de Áncash, Lima e Ica. De otro lado, José Flores Marín publicó La explotación del caucho en el Perú (1977), donde detalló la inserción de la economía cauchera (1880-1910) en el contexto del capitalismo dependiente y sus nefastas consecuencias sobre las poblaciones amazónicas.

En 1977, los sociólogos Clemente Soto, Arturo Urbano y Zenón Vargas, publicaron su trabajo Aproximación metodológica. Empobrecimiento absoluto y relativo. Paramonga. Allí, empleando conceptos marxistas, estudian la pauperización de la clase obrera producida por la ley de acumulación capitalista en el complejo agroindustrial Paramonga durante el período 1960-1967. Los autores destacan la participación de diversos factores en el proceso de pauperización, como las bajas remuneraciones y deficiente nivel de los servicios básicos (vivienda, salud, etc.), y ponen énfasis en el fracaso del modelo cooperativo para revertir esta situación de los trabajadores agrícolas. A su vez, Wilsón Reátegui en su texto Explotación agropecuaria y movilizaciones campesinas en Lauramarca: Cuzco, aborda el proceso de conversión de la Sociedad agrícola y ganadera Lauramarca S.A. en la Cooperativa agraria de producción Lauramarca Ltda. El autor consultó informes de la Sección Indígena del Ministerio de Trabajo y de la Oficina de Reforma Agraria en Cuzco, a fin de exponer la prolongada lucha campesina contra los latifundistas y el régimen de servidumbre durante el siglo XX.

\section{Segunda fase: El giro hacia los estudios sectoriales y conceptuales (1979-2000)}

Durante los años comprendidos entre 1979 y 2000, el SHRA amplió sus líneas de investigación, añadiendo a las conocidas series estadísticas varios estudios sobre aspectos teóricos (metodológicos y conceptuales) y diversos sectores de la economía nacional. Según Heraclio Bonilla, durante estos años hubo "nulo o escaso interés" por la historia económica en el contexto historiográfico nacional, pues "el rigor y la exigencia que requiere la formación y la práctica de la historia económica" alentaba la "deserción" de las nuevas generaciones de historiadores, encantadas por la historia de

56 Macera, Prólogo en Huertas, 1974: V.

57 Macera, Prólogo en Carbone, 1976: 2. 
las mentalidades.$^{58}$ En el decenio de 1980, el SHRA continuó publicando clásicos de la literatura económica, ensayos de inspiración marxista sobre burguesía y proletariado, y series estadísticas de precios y diezmos coloniales y republicanos. Francisco Quiroz y José Ballesteros, egresados de la Universidad de Moscú, publicaron Génesis de la burguesía nacional peruana y Formación del proletariado en el Perú, respectivamente. Dichos textos fueron incluidos en el volumen I de la Bibliographic Guide to Latin American Studies, publicada en 1984.

En esta fase, Pablo Macera y sus colaboradores (Rosa Boccolini, Nadia Carnero, Rosario Jiménez, Álvaro Goicochea y Honorio Pinto) publicaron catorce textos con documentos del Archivo Nacional de Sucre recopilados en el transcurso de su visita a Bolivia en 1977. Macera había reparado en la importancia de estos materiales desde mediados de la década de 1960. Al respecto, en 1970 circuló un memorándum sobre este tema entre varios especialistas. ${ }^{59}$ Con estos trabajos el SHRA organizó la Biblioteca Andina. Fuentes de Historia Social Americana. Los catorce volúmenes de la serie dedicada a Bolivia aparecieron entre 1978 y 1993. Sobre la contribución del SHRA a la historiografía boliviana, Herbert Klein precisa que "mucha documentación importante sobre la vida rural y urbana del siglo XIX en Bolivia ha sido reunida por varios estudiantes peruanos bajo la dirección de Pablo Macera en las Fuentes de Historia Social Americana" ${ }^{60}$ Los dos primeros llevaron los títulos de Bolivia, tierra y población, 1825-1936 y Bolivia, tierra y población, 1844-1939, y contienen valiosa información estadística sobre censos, registros de contribuyentes, comercio local, producción agropecuaria, diezmos y catastros correspondientes a los diferentes departamentos, provincias y cantones bolivianos.

Otros cinco textos abordaron la cuestión tributaria en el país altiplánico. Estadísticas de contribución indígena en Bolivia, 1770-1902, preparado por Rosa Boccolini y Rosario Jiménez, registra la evolución del tributo indígena de seis departamentos bolivianos (Chuquisaca, Cochabamba, La Paz, Oruro, Potosí y la Mar) en el período citado. A su vez, Contribución indígena en Bolivia, 1829-1911 (Documentos), elaborado por Honorio Pinto, reunió 30 documentos que revelan cómo la formación de la hacienda republicana de Bolivia estuvo sustentada en la persistencia del tributo indígena, con grave perjuicio de los pueblos empobrecidos. Por su parte, Álvaro Goicochea editó Documentos sobre el sector urbano en Bolivia. 1756-1877, con informes sobre censos, impuestos a los alimentos y pobreza. En 1984, el texto Diezmos del Alto Perú: Chuquisaca, siglos XVII-XIX, publicado por Francisco Quiroz, reconstruyó mediante cuadros y gráficos las tendencias en el cobro de los diezmos al interior de cinco diócesis bolivianas (Chuquisaca, Charcas, Cochabamba, Santa Cruz y Oruro), y analizó el impacto que estos tuvieron sobre la economía rural y campesina. Más tarde, circuló Los indios de Bolivia, 1825-1881. Documentos (1993), compilación de papeles del Archivo Nacional de Bolivia efectuada por Yolanda Candia, que trata acerca de la contribución indígena y la resistencia suscitada por su cobro forzado.

En 1980, Los militares en el presupuesto boliviano de Esperanza Soto, reveló cuánto le costó al Estado boliviano mantener a su fuerza pública (militares, policía y guardia nacional) durante el siglo XIX (1831-1900), y calculó que el porcentaje del presupuesto destinado al gasto militar osciló entre el 25\% y 63\%. Años después, Pablo Macera seleccionó 66 documentos del Archivo de Sucre para editar dos volúmenes titulados Mojos y Chiquitos 1768-1820 y Mojos y Chiquitos 1825-1856, que describen la situación económica de estos territorios después de la expulsión de los jesuitas y aportan datos del comercio, tributación y estadísticas agrícolas durante las primeras décadas de

58 Bonilla 1996: 122

59 Pinto 1979: I.

60 Klein 2003: 289. 
vida independiente de Bolivia. En Cascarilla de Bolivia, siglo XIX (1991), Macera eligió documentación que traza la historia de la explotación de dicho recurso, desde la época del monopolio colonial hasta los años de la comercialización privada bajo control del Estado y la aplicación de políticas para aumentar su consumo internacional. En esa serie incluimos también tres trabajos sobre minería boliviana. Minería en Bolivia, 1826-1848 (1979) de Rosario Jiménez y Honorio Pinto, identificó los factores (escasez de capital y mano de obra, uso de técnicas anticuadas, etc.) que causaron la decadencia de dicha actividad en las décadas posteriores a la independencia. A su turno, Pablo Macera reunió 69 documentos que publicó en dos volúmenes titulados Minería de Bolivia, 1801-1872 (1989) y Minería de Bolivia 1829-1849 (1991), donde se ocupa de las instituciones fundadas por el Estado boliviano para impulsar el fomento minero y la amonedación de plata.

En estos años, los estudios sobre contribuciones estuvieron representados por doce trabajos. Pablo Macera había alertado veinte años antes sobre el desconocimiento de las rentas eclesiásticas, pues ningún historiador mostraba interés en estudiar los diezmos, expolios, cofradías, etc. En ese contexto, Josep Fontana consideró de suma importancia las publicaciones del SHRA sobre diezmos, pues estos constituyen indicadores de la producción, comercialización y tráfico de bienes agropecuarios ${ }^{61}$ Por esa razón, Miguel Pinto y Nadia Carnero, emplearon documentos del Archivo Arzobispal de Lima para editar Diezmos en Lima 1592- 1859 (1983), con el propósito de que los datos estadísticos registrados pudieran emplearse como "indicadores de fenómenos sociales y económicos". ${ }^{62}$ Nadia Carnero y Lorenzo Huertas consultaron papeles de los archivos eclesiásticos arequipeño y cuzqueño para sus trabajos Diezmos en Arequipa, 1780-1856 y Diezmos del Cuzco, 1777-1853. En ambos casos, el estudio de esa tasa tributaria debía descubrir el "abanico de factores" que incidían en la producción y circulación de bienes agrícolas dentro de cada diócesis. ${ }^{63}$ De esa forma, pensaban establecer indicadores "que permitan evaluar retrospectivamente el producto agrario en el Perú durante la época colonial y el siglo XIX republicano”. ${ }^{64}$ Lorenzo Huertas culminó esta serie con su texto Tierras, diezmos y tributos en el obispado de Trujillo. Colonia-República (1984), cuyo principal mérito fue "detectar" los polos de mayor desarrollo relativo dentro de las regiones encerradas en el obispado de Trujillo, que abarcó "las tres regiones clásicas de la geografía peruana (costa, sierra y oriente amazónico)". ${ }^{5}$

Gabriela Ramos y Pedro Guibovich en un balance sobre la investigación histórica de esta época reconocieron la importancia de las series sobre diezmos del SHRA, si bien lamentaron "que tan encomiable y arduo trabajo" tuviese escasa difusión y “acceso difícil”, más aún cuando, en su opinión, el IEP parecía haber abandonado el estudio de la historia agraria de la Colonia.66 Con todo, los textos sobre precios de Pablo Macera, Rosa Boccolini y Rosario Jiménez han sido consultados por varios historiadores, como David Fischer (1996), Ruggiero Romano (1993) y Enrique Tandeter (1983). Asimismo, los trabajos sobre diezmos de Nadia Carnero, Lorenzo Huertas y Miguel Pinto fueron revisados por Carlos Buller (2007), Francisco Cervantes (1999), Nelson Manrique (1985), Enrique Tandeter (1990) y Joanne Pillsbury (2008). Por esos años, el SHRA promocionó también las investigaciones de jóvenes historiadores, como Magdalena Chocano y Cecilia Méndez. Referencias al texto Comercio en Cerro de Pasco a fines de la época colonial (1982) de Magdalena Chocano pueden encontrarse en Margarita Menegus (2000) Neus Escandell-Tur (1997) y

61 Fontana 1988: 108.

62 Carnero y Pinto 1983: 2.

63 Huertas y Carnero 1983a: VI.

64 Huertas y Carnero 1983b: 2.

65 Macera, Prólogo a Huertas, 1984: 9.

66 Ramos y Guivobich 1991: 174-175. 
John Fisher (2000). A su vez, las ideas expuestas por Cecilia Méndez en su texto Los trabajadores guaneros del Perú, 1840-1879 fueron desarrolladas en el artículo "La otra historia del guano. Perú (1840-1879)" publicado por la Revista Andina en julio de 1987, generando debate sobre la explotación de los trabajadores de las islas guaneras. Poco después, Pablo Macera compiló 142 documentos de archivos arequipeños para preparar los volúmenes Geografía colonial de Arequipa. Descripciones y Geografía colonial de Arequipa. Rentas eclesiásticas (1989). Ambos recogen informes de autoridades civiles y religiosas acerca de las condiciones socio-económicas de los curatos arequipeños y las rentas que estos producían en el marco de la reforma fiscal emprendida a fines del siglo XVIII.

De otro lado, los temas agrarios ocuparon gran parte de la producción historiográfica del SHRA en esta fase. Así, con documentos del Archivo de la Nación, Esperanza Soto publicó Propiedad rural en Lima, 1837 (1980), donde precisó la forma en que estaba repartida entonces la tierra agrícola de los valles limeños. Al año siguiente, César Espinoza centró su trabajo Terratenientes y campesinos de Piura. Comunidades de Colán y Amotape: Siglos, XVI-XIX (1981) en el estudio de la lucha por la tierra, atizada con la llegada del capital extranjero y activa incluso bajo la Reforma Agraria de 1968. En esa misma línea, Fernando Ponce publicó Tierra y desigualdad. Estudio sobre la estructura de la propiedad rústica y el ingreso agrario de nueve provincias del Perú, a mediados del siglo XIX (1985), cuyo objetivo fue precisar cómo se distribuyó la tierra, el volumen de ingresos y los circuitos económicos derivados de la actividad agrícola en un contexto de expansión producido por las rentas del guano. Alejandro del Río retomó el tema de la hacienda colonial con su estudio Ninabamba. Una hacienda jesuita del siglo XVIII- Huamanga (1987), donde analiza el funcionamiento interno de esta bajo la administración jesuita y la constituida después de su expulsión.

Entre tanto, la formación universitaria en historia económica carecía de rigurosidad en "áreas específicas". Los estudiantes de la Pontificia Universidad Católica del Perú (PUCP) afrontaban muchas dificultades en "tratar adecuadamente fuentes cuantitativas" ${ }^{67}$ mientras en la UNMSM se produjo un marcado descenso en la calidad de los trabajos historiográficos por las circunstancias de violencia política que afectaron la vida académica. ${ }^{68}$ En ese ambiente sobrevino el cuestionamiento de la Nueva Historia coincidente con el declive del marxismo a nivel mundial. Esto condujo a que el decenio de 1990 fuese una época de intensa búsqueda por ofrecer nuevas perspectivas de investigación histórica en medio de los rezagos marxistas y la influencia de las historiografías norteamericana y europea. Un breve análisis sobre este proceso de renovación historiográfica podemos encontrarlo en el artículo "La historiografía peruana en debate" de Juan Carlos Estenssoro y otros. ${ }^{69}$ Dos trabajos de Paul Gootenberg iniciaron el debate cuestionando la teoría dependentista que culpaba al capitalismo inglés del atraso del Perú. Estos textos fueron Between silver and guano: commercial policy and the state in postindependence Peru, (1991) e Imaginar el desarrollo: las ideas económicas en el Perú postcolonial (1998). Gootenberg, por el contrario, atribuyó este hecho a la supervivencia de las estructuras coloniales y la anarquía política, que paradójicamente cerró la economía al dominio británico mediante políticas proteccionistas. ${ }^{70}$

De igual forma, Alfonso Quiroz (Banqueros en conflicto Estructura financiera y economía peruana, 1884-1930 (1989) y Felipe Portocarrero (El imperio Prado: 1890-1970, 1995) coincidieron

67 Contreras 2011: 116-117.

68 Loayza 2011: 16.

69 Estenssoro y otros 1993: 113-120.

70 Contreras 2003: 8-9. 
en afirmar que el fracaso de la burguesía nacional había sido producto de limitaciones internas y no por causa de factores externos. Otros historiadores apelaron a "reinterpretaciones" de los argumentos de la Nueva Historia para estudiar aspectos desconocidos o subestimados anteriormente, como la historia empresarial peruana. ${ }^{71} \mathrm{Al}$ respecto, las investigaciones de Carlos Contreras sobre tributación y minería en la Colonia y Republica plantearon una perspectiva novedosa que conjugó aportes de las antiguas "interpretaciones" y de las "nuevas posturas" de la historiografia económica peruana.72 Este proceso de cambio también fue animado por los estudiantes a través de coloquios, conferencias y publicación de revistas.73

Este ambiente de renovación conceptual estimuló en el SHRA la publicación de ensayos sobre cuestiones conceptuales y metodológicas. Esta tarea fue iniciada con el texto Método y producción teórica en la historia económica (1979) de Javier Tantaleán, orientado a debatir la posibilidad de construir una teoría marxista de la historia económica y activar la producción de conocimientos “a partir de ese marco teórico”. Desde esa misma perspectiva, Formación del proletariado en el Perú (1982) de José Ballesteros rastrea aquellos factores condicionantes del surgimiento de la clase obrera y su posterior evolución vinculada al desarrollo del capitalismo en el Perú. Poco después, Génesis de la burguesía nacional peruana (1982) de Francisco Quiroz investigó las peculiaridades del "modo de producción burgués" en el Perú y las "condiciones concretas" que ejercieron influencia en la formación de la clase capitalista. Desde esa perspectiva marxista, Carlos Dávila en Modo de producción asiático. Un debate historiográfico inconcluso (1999) sostiene la necesidad de utilizar la "teorización" surgida en torno a dicho concepto para estudiar la "resistencia étnica” y caracterizar a las sociedades indígenas amazónicas como representaciones del modo de producción asiático en proceso de transición hacia la economía de mercado. En 1998, El circuito macroeconómico incaico de Javier Tantaleán propuso esbozar una "lógica del crecimiento de la sociedad incaica" utilizando métodos de la macroeconomía, pues los elementos teóricos modernos permiten comprender las relaciones productivas de las sociedades antiguas. Este mismo autor en su trabajo Un enfoque económico neoclásico de la idea colonial sobre la flojera del indio. Cataclismo en el Imperio Inca. El impacto hispano: ¿Eclipse demográfico en los Andes, ocaso en la costa (siglo XVI)? (1999) resume el debate histórico surgido en torno a la capacidad laboral y productiva de los indios, y analiza la sobreexplotación de estos como causa de la despoblación de la costa durante la conquista hispana.

Otras publicaciones se enfocaron en cuestiones mineras, comerciales y laborales. Minas e indios del Perú, siglos XVI-XVIII (1981) de Nadia Carnero, surgió como resultado del descubrimiento de varios papeles inéditos empastados en la Biblioteca de la Universidad de Ingeniería. Esos documentos ofrecieron datos cruciales sobre tasas, mitas y la forma periódica en que estaba organizado el trabajo de los indios en las minas y la magnitud del excedente extraído de dicha fuerza laboral. Asimismo, el impacto de la minería en el desarrollo de otras ramas productivas dentro del mercado regional de la sierra central fue estudiado por Magdalena Chocano en su texto Comercio en Cerro de Pasco a fines de la colonia (1982). Mario Egoavil, en cambio, a través de su texto Comercialización de la quinua en el Altiplano peruano (1983), identificó los agentes y formas (tradicionales y modernas) que intervenían en el intercambio de este grano andino a fines del decenio de 1970. De otro lado, en 1987, Cecilia Méndez editó Los trabajadores guaneros del Perú, 1840-1879, que centró su interés en las relaciones sociales implicadas en la explotación del guano,

71 Drinot 2008: 239-240.

72 Contreras y Cueto 2000: 463.

73 Loayza 2011: 17. 
la situación y características de la fuerza laboral (culíes, presidiarios, peones libres) y las formas de respuesta de los trabajadores a ese sistema de explotación. Más tarde, Francisco Quiroz reunió 16 documentos cedidos por Pablo Macera para elaborar el texto Gremios coloniales peruanos (1991), donde examina las dos funciones cumplidas por estas corporaciones: la inserción de las clases populares en la producción urbana y el ordenamiento social fragmentado de las castas.

En una categoría singular incluimos los trabajos sobre instituciones y los textos clásicos de economía colonial y republicana. En 1980, el presbítero Luis Ramírez publicó una "síntesis histórica" titulada Tribunal Mayor de Cuentas. Dicho texto, escrito "con objetividad, pero sin frialdad" detalla cómo el desarrollo del citado tribunal estuvo condicionado por "el proceso político y administrativo general del Perú”.74 Las Cofradías en Lima, siglos XVII-XVIII (1986) de Teresa Egoavil analizó el papel cumplido por estas asociaciones religiosas coloniales, cuya estructura jerárquica y administración de fondos comunes estuvo bajo el control de la Iglesia a través del cobro de limosnas o imposición de censos o capellanías. A estos textos debemos agregar cuatro clásicos de la literatura económica. Breves reflexiones sobre los sucesos ocurridos en Lima y Callao con motivo de la importación de artefactos de José Silva Santisteban (1979), apareció originalmente en 1859 como respuesta a la protesta artesana de 1858 contra la importación de artefactos y con el objeto de convencer a las masas de los perjuicios del proteccionismo. Mercaderes de la plata (1982) reproduce el informe del funcionario colonial Joseph Rodriguez de Carassa acerca del laboreo minero y la amonedación de plata en el siglo XVIII. Con similar intención, el Informe económico de Piura, 1802 (1984) de Joaquín Helguero recogió información sobre la calidad de la tierra, tipos de cultivo y conflictos sociales, y propuso impulsar la industria del algodón piurano. Finalmente, El Tesoro del Perú (1992), editado por José Clavero en 1896, compiló información económica de distinta procedencia, destacó la importancia de las series cuantitativas y calculó el ingreso per cápita en el Perú y demás países americanos.75

En este contexto de redefinición de las bases teóricas y metodológicas de la Historia, Pablo Macera y un grupo de jóvenes historiadores (Rosaura Andazabal, Luz Peralta, Omar Rojas, Sonia Challco, Juan y Sara Fuentes) del SHRA privilegiaron el estudio y publicación de fuentes sobre contribuciones eclesiásticas y pleitos por tierras entre indios y españoles bajo el régimen colonial, a partir de información contenida en los archivos Arzobispal de Lima y de la Nación. El aspecto tributario fue abordado por Rosaura Andazabal en su texto Tributos, linajes y pleitos de tierras: Guayaquil 1800-1819 (1993), que registra datos sobre la caja real y padrones de tributarios guayaquileños. Por su parte, Sonia Challco en su texto Visitas eclesiásticas. Áncash Ss. XVII-XVIII (1995) seleccionó 35 informes del Archivo Arzobispal de Lima referidos a ingresos y egresos y pagos de primicias en varios pueblos de Áncash entre 1622 y 1774. En simultáneo, Sara y Juan Fuentes Sánchez apelaron a similar fuente para editar Padrones de feligreses y rentas de los curatos de Ica. Siglos XVII-XVIII (1995) y Padrones de feligreses y rentas de los curatos de Ica. Siglo XIX (1996), que contiene minuciosa información de los recursos poseídos por los curatos iqueños. Luz Peralta y Miguel Pinto, en cambio, se interesaron por los derechos aduaneros coloniales en su trabajo Asiento de los reales almojarifazgos, 1635 (1997). De otro lado, Rosa Boccolini y Rosario Jiménez en su texto Matrícula de contribuyentes, 1896 (1994), reprodujeron las cifras sobre recaudación de contribuciones de varios períodos del siglo XIX (1860-1863, 1867-1872, 1884-1885) anotadas en tres libros oficiales de cuentas. Asimismo, Indios, tierras y caciques del Perú, siglos XVIII-XIX (1993) de Rosaura Andazabal y Omar Rojas examina los litigios coloniales por tierras y

74 Macera, Prólogo a Ramírez 1980: 1.

75 Pinto, Prólogo a Clavero 1992: IX. 
los perjuicios causados a caciques e indios. Por último, Composición y tenencia de tierras/valle de Paucartambo, Cuzco, siglos XVI-XVIII (1994) de Sonia Challco describe la intensa disputa entre hacendados y religiosos por despojarse mutuamente de tierras en esta región.

\section{Tercera fase: La apertura de nuevas líneas de investigación. Estudios monetarios y sobre rentas fiscales republicanas (2001-2015)}

El inicio de la tercera fase (2001-2015) coincidió con el término de la gestión directoral de Pablo Macera, que en adelante centró su interés en la recopilación y análisis de las tradiciones orales andina y amazónica. Bajo las sucesivas gestiones de los nuevos directores (Jaime Miasta, Nanda Leonardini, Honorio Pinto y Emilio Rosario), la investigación de cuestiones económicas continuó, pero con menor preponderancia que en las fases anteriores.

En el largo período constituido por los últimos quince años, la producción historiográfica ha crecido notablemente ampliando los temas de investigación de nuestra historia económica. La formación de grupos de estudios y la publicación de nuevas revistas de estudiantes desde el año 2000 han permitido además una mayor comunicación y colaboración entre docentes y jóvenes investigadores. Mención especial merece la labor editorial del Banco Central de Reserva del Perú (BCRP) y el IEP, que bajo la dirección de Carlos Contreras, han publicado 25 textos sobre historia económica desde el año 2008. Esta serie incluyó trabajos de Shane Hunt, Nils Jacobsen, Carlos Contreras, Vincent Peloso, Rory Miller, Francisco Quiroz, William Mathew, Juvenal Luque, Cristina Mazzeo, José Deustua, Javier Tantaleán y otros.

Notable resulta también la realización de investigaciones históricas por parte de varios economistas. Bruno Seminario ha construido series sobre cuentas nacionales, población y precios desde la Colonia hasta la actualidad, que pueden consultarse en su texto El desarrollo de la economía peruana en la era moderna: precios, población, demanda y producción desde 1700 (2015). Luis Felipe Zegarra utilizó conceptos e indicadores de la ciencia económica para plantear un novedoso análisis sobre la línea de pobreza y salarios en el primer cuarto del siglo XX recogidos en su trabajo "Línea de pobreza y salarios, 1913-1925: una primera aproximación” (2011). Por su parte, Efraín Gonzáles de Olarte enfoca los principales aspectos que han condicionado el desarrollo parcial de nuestra economía desde mediados del siglo XX en su trabajo Una economía incompleta Perú 19502007: análisis estructural (2015).

Hubo también creciente interés por el estudio de las élites económicas (Francisco Durand y Enrique Vásquez) y la historia de la corrupción en el manejo de los fondos públicos (Alfonso Quiroz). Felipe Portocarrero estudió los mecanismos empleados durante el siglo XX por la elite peruana para enriquecerse han sido analizados por Felipe Portocarrero en su texto Grandes fortunas en el Perú: 1916-1960. Riqueza y filantropía en la élite económica (2013). Francisco Durand analizó el encumbramiento de la elite financiera en su trabajo Los Romero. Fe, fama y fortuna (2014). De otro lado, la influencia ejercida en la política económica por los nuevos grupos empresariales ha sido examinada por Enrique Vásquez en su texto Estrategias del poder. Grupos económicos en el Perú (2000). Asimismo, Alfonso Quiroz trazó el penoso cuadro de la crónica corruptela que afectó las finanzas públicas republicanas. Para tener una idea exacta del perjuicio causado al erario por las diversas formas de corrupción conviene revisar el texto Historia de la corrupción en el Perú (2013).

De otro lado, en los últimos cinco años, los historiadores graduados en la UNMSM han abordado temas del siglo XX, mientras los de la PUCP se enfocan en la época colonial y prehispánica. 
En el primer caso, merecen destacarse las tesis La construcción de las políticas industriales en el Perú, 1930-1939 (2013) de Franco Lobo e Implicancias de la Reforma Agraria en el campesinado y la desarticulación conflictiva de la cooperativa agraria de producción: El caso de Antapampa (2015) de Jorge Sarmiento. En el segundo caso, mencionaremos las tesis Las finanzas del fervor. Las prácticas económicas en el Monasterio de Santa Catalina de Lima, 1621-1682 (2013) de Javier Espinoza, El tráfico de afroandinos en el valle de Jauja durante el siglo XVII (2011) de Eduardo Barriga y El modelo económico de Murra sobre los Andes prehispánicos: alcances y limitaciones (2011) de Carlos Garaycochea.

En este mismo período (2001-2015), el SHRA no solo produjo textos compuestos por fuentes precedidas por estudios introductorios, sino también investigaciones enfocadas en nuestra economía decimonónica. Entre los años 2001 y 2002, Luz Peralta publicó cuatro trabajos sobre economía colonial. El primero, titulado Avaliación de mercaderías en Lima, 1562, reproduce un documento con datos de las mercancías importadas por el puerto del Callao en dicho año, clasificándolas por series y porcentajes. El segundo denominado Censos y capellanías de las casas religiosas de Ayacucho y Huancavelica, entrega una minuciosa relación de las casas, haciendas y chacras afectas por estas imposiciones religiosas en las zonas citadas hacia 1828, y registra además a los titulares de los censos y capellanías con los réditos anuales que estos rendían. Por su parte, Composición de una viña jesuita en Arequipa. Vitor, 1656 reveló los mecanismos políticos y jurídicos empleados por la eficiente administración jesuita para conservar la extensión y abasto de agua de la citada propiedad rural. A su vez, Pleito de tierras en Ámbar, Cajatambo, Siglo XVIII, detalla las tensiones surgidas entre las haciendas y ayllus de esta provincia por la posesión de las tierras de cultivo.

Debo referirme también a las investigaciones económicas que he efectuado en el SHRA. Desde el año 2001, inicié la exploración de nuevos fondos documentales y material hemerográfico para continuar el objetivo fundacional del SHRA por construir una visión integral de los diversos rubros que componen la economía peruana y trazar el derrotero de la hacienda pública y las economías individuales decimonónicas, incidiendo en los factores internos y externos que provocaron su permanente crisis. En ese sentido, mi texto Estadística y contribuciones en el Perú. Siglo XIX (2001) analizó el complejo panorama de la fiscalidad posindependiente, a partir de cifras contenidas en los documentos publicados por Pablo Macera en sus cuatro volúmenes de Tierra y Población siglos XVIII-XIX. De ese modo, revelamos los defectos del esquema fiscal impuesto en la posguerra de la Independencia, producto de la carencia de estadísticas y la fijación de tasas tributarias que no guardaban relación con los ingresos particulares, circunstancias generadoras de corruptela en la cobranza de los tributos y una constante evasión de los contribuyentes.

Después examiné la depreciación monetaria que afectó la economía nacional entre la Independencia y el inicio de la Guerra del Pacífico. Esta investigación dio como resultado la edición del texto Cuatros y billetes. Crisis monetaria peruana, 1821-1879 (2006), que atribuyó las causas de la desmonetización de la economía republicana a dos aspectos: la constante exportación de moneda como resultado de las desiguales relaciones de intercambio establecidas con los principales centros del mercado internacional, y el desfase surgido entre la oferta interna de metales y las políticas fiscales (proteccionistas o liberales) adoptadas para equilibrar las balanzas comercial y de pagos. Este trabajo ha sido incluido en el trabajo Fuentes documentales e historia monetaria (2014) del historiador Dionisio de Haro, publicado por el Instituto Riva Agüero. Además, el año 2011, gracias a una invitación de Carlos Contreras, el BCRP y el IEP publicaron una nueva edición de los Cuatros y billetes.

De igual modo, estudié la privatización de la red ferroviaria en la posguerra del Pacífico y las repercusiones de ese hecho sobre la fiscalidad y márgenes de ganancia de mineros y agroexporta- 
dores, trabajo que dio como resultado la publicación del texto Capital extranjero y ferrocarriles, 1884-1899 (2008), En este período, la concesión de ferrocarriles a los bonistas ingleses, acordada mediante el Contrato Grace, favoreció la incursión del capital extranjero en sectores básicos de la economía nacional. Dicho proceso de desnacionalización ferroviaria generó una red clientelista (lobby) que obtuvo de los poderes públicos la sanción de sus proyectos empresariales. En el curso de una década (1890-1899) la Peruvian Corporation controló la red ferroviaria e impuso altos fletes a mineros y productores agropecuarios de la sierra central y surandina. Las controvertidas operaciones financieras, impulsadas por los representantes de dicha empresa británica y criticadas duramente en la prensa y el Congreso, fueron convalidadas por una clase política ilusionada con el mito de la inversión extranjera, cuyo estrepitoso fracaso condujo al país a perder sus principales rentas fiscales y optar por la implantación de un nuevo modelo tributario a fines del siglo XIX.

La huaneyda. Historia del huano, 1840-1879, publicado el año 2009, abordó el impacto de la explotación del huano en el manejo de la hacienda pública y el surgimiento de un pensamiento económico orientado a convertir la riqueza generada por este fertilizante en industrias permanentes u obras de infraestructura que ampliaran la capacidad productiva del país. A pesar de este propósito, los consignatarios huaneros terminaron incentivando los gastos suntuarios y hábitos rentistas entre la población. La historia del huano puede dividirse en dos grandes etapas: una primera (1840-1860), donde la exportación de este abono creció rápidamente en medio de pugnas entre la Casa Gibbs y los capitalistas nacionales, y otra segunda (1860-1879), de marcada decadencia por causa del lesivo Contrato Dreyfus, la sobreexplotación de los yacimientos y la pérdida de mercados por efecto de la competencia del salitre nacional y extranjero. Este trabajo además analizó la influencia ejercida por el lobby huanero sobre el Gobierno y Congreso durante el período citado, y precisó los cambios económicos, sociales y culturales producidos por el aburguesamiento derivado del espejismo de bonanza fiscal.

Ese mismo año, el texto Las rutas del café y el trigo: Los ferrocarriles de Chanchamayo y Huancavelica, 1886-1932, escrito en coautoría con Miguel Pinto, expuso cómo los circuitos tradicionales de los mencionados productos agrícolas dieron origen a dos nuevos proyectos ferroviarios peruanos, entre fines del siglo XIX y principios del siglo XX. La primera ruta formaba parte del proyectado ferrocarril oriental, llamada también de Chanchamayo, que por diversas circunstancias, geográficas, económicas y políticas no llegó a construirse. La segunda ruta constituía una sección del futuro ferrocarril longitudinal andino diseñado para conectar la sierra central y sureña con la línea del Ferrocarril Central. De esa manera, los gobiernos de la posguerra del Pacífico pensaron establecer una vasta red ferroviaria cuyos extremos serían Lima y Cuzco. Para recoger los estudios y opiniones de quienes intervinieron en las discusiones sobre la factibilidad de estas rutas se consultaron los Diarios de Debates de la Cámara de Diputados y de Senadores, artículos publicados en los diarios El Comercio, El Peruano y La Prensa, así como folletos y revistas de aquella época.

Durante estos años, Santiago Tácunan puso énfasis en la investigación de la actividad del capital británico en el Perú. En su texto Peruvian Corporation. Informes de gerentes, 1920-1961 (2008), describe cómo fue administrada esta empresa, las crisis económicas que debió afrontar y los préstamos obtenidos de bancos mundiales en 1958 y 1963 para continuar operando. Incluye además cinco informes financieros suscritos por sus gerentes en los años 1920, 1932, 1939, 1951 y 1961, los cuales contienen interesantes opiniones acerca de nuestra sociedad y economía. Asimismo, el trabajo Colonia del Perené, Presencia inglesa en la Amazonía peruana (2009) reseña la historia de este proyecto colonizador, que fracasó por causa de dificultades logísticas y su escasa articulación con los mercados interno y externo. Por su parte, Honorio Pinto reunió normas legales, notas periodísticas, cuadros 
estadísticos con los cuales preparó tres textos que ofrecían una cronología de los conflictos socioeconómicos generados durante la última década por la actividad de las empresas mineras extranjeras. Sus trabajos Doe Run Perú en La Oroya: 1997-2008 y Doe Run Perú en La Oroya: 1997-2009 cuestionan a esta empresa por incumplir la responsabilidad social empresarial con respecto a la contaminación ambiental y anexa documentos que sustentan dicha crítica. Gran minería en el Perú: El caso Barrick Misquichilca (2009) aborda el proceso de transnacionalización de la minería aurífera, a partir de la presencia de la Barrick Gold Corporation en territorio peruano. Similar enfoque se presenta en Gran minería en el Perú: el caso Shougang Hierro Perú S.A.A. (2011), referido a la inversión de capitales chinos en el complejo minero de Nazca en 1992.

Posteriormente, Polos opuestos: salarios y costo de vida 1821-1879, publicado el año 2013, analizó los factores determinantes en la evolución del costo de vida en Lima y principales ciudades del interior durante el siglo XIX. En primer lugar, la creciente inflación erosionó constantemente el poder adquisitivo de las clases populares decimonónicas. Asimismo, la formación de los precios agropecuarios estuvo condicionada por los modelos tributarios adoptados, la devaluación monetaria, el agiotismo y la especulación mercantil. Por lo demás, las escalas salariales fueron muy diversas, debido a las marcadas diferencias entre los jornales urbanos y rurales, y los niveles de carestía imperantes en cada región. A partir del estudio comparado de esas variables, este trabajo se planteó tres objetivos: a) detallar los cambios ocurridos en la composición del ingreso salarial, b) señalar los mecanismos empleados por los gobiernos para atenuar el costo de vida, y c) examinar los reclamos y movilizaciones de las clases populares y medias contra la escasez o encarecimiento de víveres. La Primera Encuesta Anual de Los Mejores Libros de Historia del 2013, realizada por el blog El Reportero de la Historia, incluyó esta publicación entre las diez más destacadas de dicho año.

Por último, exploré la crisis del cambio de patrón monetario que condicionó la reconstrucción económica emprendida desde 1884. El ocaso del sol de plata. Moneda y economía, 1880-1897, editado el año 2015, estudió la crisis monetaria en la posguerra del Pacífico, agudizada por la fallida creación del inca de oro (1880), la ruina del billete fiscal y el establecimiento del patrón áureo (1897). El bimetalismo de emergencia surgido durante la guerra externa sucumbió por su debilidad estructural y el boicot chileno. Los gobiernos de la Reconstrucción Nacional, carentes de soles de plata, apelaron al papel moneda para reordenar la economía nacional, Sin embargo, finalmente debieron repudiarlo y convertirlo en deuda interna en medio de la carestía de víveres y desmonetización del sur andino. Más tarde, Gobierno y Congreso, presionados por comerciantes y exportadores, prolongaron el ocaso del sol de plata hasta 1897, cuando recién autorizaron la acuñación de piezas peruanas de oro. El citado texto se propuso tres objetivos: a) precisar el impacto de la depreciación del sol de plata en el manejo de la hacienda pública, b) exponer cómo la inestabilidad monetaria redujo el patrimonio privado y la capacidad adquisitiva de los sectores populares, y c) analizar la influencia del debate monetario, impulsado por la prensa y los financistas (“oristas" y "platistas"), sobre la opinión pública.

\section{Conclusiones}

A manera de conclusión, conviene destacar que, en estos cincuenta años de constante investigación de asuntos económicos, el SHRA ha publicado más de un centenar de trabajos referidos a estadística y contribuciones, agricultura, minería y guano, comercio y hacienda pública, ferrocarriles, 
moneda, precios, trabajo y salarios, cuestiones teóricas y metodológicas y textos clásicos de economía, estos últimos dentro de la Biblioteca de Historia Económica. Por causa de los escasos fondos con que cuenta el SHRA, hasta el año 2001 los textos se imprimían a mimeógrafo en papel bulky con pastas de cartulina y en tirajes muy reducidos (50 ejemplares por título). Sin embargo, a partir del año 2002 son impresos en papel bond. Asimismo, desde el año 2006 las publicaciones cuentan con registro ISBN, si bien los tirajes continúan siendo cortos. Al respecto, muchos historiadores han lamentado la dificultad que afrontan para acceder a los textos del SHRA, pero actualmente la mayoría de estos pueden consultarse en la Biblioteca Nacional del Perú, la Biblioteca del del Congreso de la República, la Biblioteca Central de la UNMSM y de la PUCP. Los investigadores extranjeros también pueden consultar estas publicaciones en las bibliotecas de las principales universidades norteamericanas. De igual forma, varios de los primeros textos económicos publicados por el SHRA han sido incluidos por el Fondo Editorial del Congreso en la edición del volumen II de las Obras escogidas de Pablo Macera, facilitando su lectura a historiadores y público en general.

En medio siglo de vida institucional, el SHRA ha realizado importantes aportes y logros en cuanto a la renovación de la metodología de la historia económica. En primer lugar, constituyó un espacio académico propicio para la fundación de una escuela de historiadores económicos, que recibieron capacitación intensiva en la clasificación de los documentos y elaboración de hipótesis de trabajo tomando en cuenta los modelos empleados por la historiografía europea. En segundo lugar, proporcionó un conjunto de fuentes coloniales y republicanas sobre haciendas, demografía, tributos y exportaciones, provenientes de diversos archivos, con la finalidad de plantear nuevos temas de investigación para nuestra historiografía económica. En tercer lugar, proveyó a los historiadores de una colección de textos clásicos escritos por hacendistas de los siglos XIX y XX, que resultan indispensables para construir la historia del pensamiento económico peruano. En cuarto lugar, publicó trabajos de historiadores de diversas tendencias ideológicas, que deseaban expresar sus puntos de vista, generar debate sobre teoría económica y replantear las perspectivas de la historiografía peruana, apoyándose en la revisión de nuevas fuentes. Por estas razones, resulta encomiable el trabajo pionero emprendido desde 1966 por Pablo Macera y el SHRA para forjar una historia económica moderna y preocupada por reconstruir el devenir de aquellos factores modeladores de nuestras crisis y bonanzas hacendarias y productivas.

\section{Bibliografía}

Aguirre, Carlos (ed.) (2013). Militantes, intelectuales y revolucionarios. Ensayos sobre marxismo e izquierda en América Latina. Raleigh, North Caroline: Editorial A Contracorriente.

Aranguiz, Horacio (1967). "Pablo Macera: Instrucciones para el manejo de las haciendas jesuitas del Perú (siglos XVII y XVIII)”. Historia, 6, (3), pp. 91-393.

Barriga, Eduardo (2011). El tráfico de afroandinos en el valle de Jauja durante el siglo XVII. Lima: Pontificia Universidad Católica del Perú. Tesis de licenciatura.

Bauer, Arnold (1986). La Iglesia en la economía de América Latina, siglos XVI al XIX. México D.F.: Instituto Nacional de Antropología e Historia.

Benson Latin American Collection (1984). Bibliographic Guide to Latin American Studies. Boston: G.K. Hall.

Bonilla, Heraclio (1980). “El nuevo perfil de la Historia del Perú (1980)”. [Entrada Blog]. Reserva Crítica, Recuperado de: http://rcritica.hypotheses.org/997 
Bonilla, Heraclio. (1996) “La historia económica en el Perú en los últimos 25 años”. Socialismo y Participación, 76, pp. 117-124.

Buller, Carlos (2007). "La producción agrícola no especializada en vino de Arequipa (1772-1830)" Histórica, XXXI, (2), pp. 69-113.

Burga, Manuel (1978). "La hacienda en el Perú, 1850-1930. Evidencias y método”. Tierra y Sociedad, 1, pp. 10-38.

Burga, Manuel. (1981) "Por una historia andina y nacional. Comentarios al nuevo perfil de la historia del Perú de H. Bonilla”. [Entrada Blog]. Reserva Crítica, Recuperado de: https:// rcritica.hypotheses.org/1p

Burga, Manuel. (2005) La historia y los historiadores en el Perú. Lima: Universidad Nacional Mayor de San Marcos.

Burga, Manuel. (2014) “Para qué aprender historia en el Perú: explicaciones finales”. En: Chocano, Magdalena y otros (2014). Identidad, historia y utopía. Lima: Ministerio de Cultura.

Carbone, Pablo (1976). El problema agrario en el departamento de La Libertad. Lima: Seminario de Historia Rural Andina, Universidad Nacional Mayor de San Marcos.

Carnero, Nadia y Miguel Pinto (1983). Diezmos en Lima 1592- 1859. Lima: Seminario de Historia Rural Andina, Universidad Nacional Mayor de San Marcos.

Carnero, Nadia y Honorio Pinto $\left(1983^{\mathrm{a}}\right)$. Diezmos en Arequipa, 1780-1856. Lima: Seminario de Historia Rural Andina, Universidad Nacional Mayor de San Marcos.

Carnero, Nadia y Honorio Pinto (1983b). Diezmos del Cuzco, 1777-1853. Lima: Seminario de Historia Rural Andina, Universidad Nacional Mayor de San Marcos.

Casanova, Juan Norberto (1972). Ensayo económico-político sobre el porvenir de la industria algodonera fabril del Perú (1849). Lima: Seminario de Historia Rural Andina, Universidad Nacional Mayor de San Marcos.

Cervantes Bello, Francisco (1999). "Crisis agrícola y guerra de Independencia en el entorno de Puebla. El caso de San Martín y sus cercanías, 1800-1820”. Estudios de Historia Novohispana, 20, pp. 107-133.

Clavero, José (1992). El Tesoro del Perú. Lima: Seminario de Historia Rural Andina, Universidad Nacional Mayor de San Marcos.

Colmenares, Germán (1998). Haciendas de los jesuitas en el Nuevo Reino de Granada, siglo XVIII. Bogotá: Universidad del Valle.

Contreras, Carlos (1983). "Nuevas tendencias en la historiografía peruana. Las tesis de la Pontificia Universidad Católica del Perú, 1975-1982”. Histórica, VII, (1), pp. 111-122.

Contreras, Carlos (2002). “Notas sobre la historiografía económica en el Perú”. En: Flores Espinoza, Javier y Rafael Varón Gabai (eds.). El hombre y los Andes: homenaje a Franklin Pease G.Y. vol. I. Lima: Fondo Editorial de la Pontificia Universidad Católica del Perú.

Contreras, Carlos (2003). La teoría de la dependencia en la historia económica sobre la República. En: Documento de trabajo 216. Lima: Pontificia Universidad Católica del Perú.

Contreras, Carlos y Marcos Cueto (2000). ¿¿Qué se debe exponer en un texto de historia del Perú contemporáneo?”. Histórica, volumen XXIV, (2), pp. 461-466.

Copello, Juan y Luis Petriconi (1971). Estudio sobre la independencia económica del Perú (1876). Prólogo Jorge Basadre. Lima: Seminario de Historia Rural Andina, Universidad Nacional Mayor de San Marcos.

Drinot, Paulo (2008). "Después de la Nueva Historia. Tendencias en la historiografía peruana". Illapa, 1, (2), pp. 235-255. 
Durand, Francisco (2014). Los Romero. Fe, fama y fortuna. Lima: DESCO.

Escandell-Tur, Neus (1997). Producción y comercio de tejidos coloniales: los obrajes y chorrillos del Cusco, 1570-1820. Cusco: Centro de Estudios Regionales Andinos “Bartolomé de Las Casas”.

Espinoza, Javier (2013). Las finanzas del fervor. Las prácticas económicas en el Monasterio de Santa Catalina de Lima, 1621-1682. Lima: Pontificia Universidad Católica del Perú. Tesis de licenciatura.

Estenssoro, Juan Carlos y otros (1993). "La historiografía peruana en debate”. Apuntes. Revista de Ciencias Sociales, 33, pp. 113-120.

Esteves, Luis (1971). Apuntes para la historia económica del Perú. Lima 1882. Presentación Pablo Macera. Lima: Seminario de Historia Rural Andina, Universidad Nacional Mayor de San Marcos.

Fischer, David H. (1996). The Great Wave: Price Revolutions and the Rhythm of History. New York: Oxford University Press.

Fisher, John. (2000). El Perú borbónico: 1750-1824. Lima: Instituto de Estudios Peruanos.

Flores Galindo, Alberto (1987). “Generación del 68. Ilusión y realidad”. Márgenes, 1, pp. 101-123.

Flores Galindo, Alberto (1988). "La imagen y el espejo: la historiografía peruana 1910-1986”. Márgenes, 4, pp. 55-81.

Flores Galindo, Alberto (1997). Obras completas, tomo V. Lima: Fundación Andina, SUR Casa de Estudios del Socialismo.

Fonseca, César (1973). Sistemas económicos andinos, Biblioteca Andina. Lima: Seminario de Historia Rural Andina, Universidad Nacional Mayor de San Marcos.

Fontana, Josep (1988). “Auge y decadencia de la economía del Imperio español en los siglos XVII y XVIII. Una propuesta interpretativa”. Revista ecuatoriana de historia económica, 2-3, pp. 83-111.

Garaycochea, Carlos (2011). El modelo económico de Murra sobre los Andes prehispánicos: alcances y limitaciones. Lima: Pontificia Universidad Católica del Perú. Tesis de licenciatura.

Glave, Luis Miguel (1997). "Notas sobre la historiografía andina contemporánea”. Historias. Revista de la Dirección de Estudios Históricos del Instituto Nacional de Antropología e Historia, 38, pp. 113-135.

Glave, Manuel (2011). "Reseña del libro La formación de la economía peruana: distribución y crecimiento en la historia económica del Perú y América Latina”. Revista Argumentos, 4. Recuperado de: http://revistaargumentos.iep.org.pe/articulos/resena-del-libro-la-formacion-de-la-economia-peruana-distribucion-y-crecimiento-en-la-historia-economica-delperu-y-america-latina/

Gonzales de Olarte, Efraín (2015). Una economía incompleta Perú 1950-2007: análisis estructural. Lima: Fondo Editorial de la Pontificia Universidad Católica del Perú, Instituto de Estudios Peruanos.

Gootenberg, Paul (1998). Imaginar el desarrollo: las ideas económicas en el Perú postcolonial. Lima: Instituto de Estudios Peruanos.

Gootenberg, Paul (2014). Between Silver and Guano: Commercial Policy and the State in Postindependence Peru. Princeton: Princeton University Press.

Hampe, Teodoro (1996). "Trayectoria y balance en la historiografía peruana: 90 años de la Academia Nacional de la Historia (1905-1995)”. Boletín del Instituto Riva-Agüero, 23, pp. 39-61.

Haro, Dionisio de (2014). Fuentes documentales e historia monetaria. Lima: Instituto Riva Agüero, Pontificia Universidad Católica del Perú. 
Huertas, Lorenzo (1974). Capital burocrático y lucha de clases en el sector agrario. Lambayeque, Perú, 1920-1950. Lima: Seminario de Historia Rural Andina, Universidad Nacional Mayor de San Marcos.

Huertas, Lorenzo (1984). Tierras, diezmos y tributos en el obispado de Trujillo. Colonia-República. Lima: Seminario de Historia Rural Andina, Universidad Nacional Mayor de San Marcos.

Instituto de Estudios Peruanos (1968). El Instituto de Estudios Peruanos. La institución y sus actividades (1964-1968). Lima: Instituto de Estudios Peruanos.

Klein, Herbert (2003). A Concise History of Bolivia. Cambridge: Cambridge University Press.

Konrad, Herman (1989). Una hacienda de los Jesuitas en el México colonial: Santa Lucía, 15761767. México D.F.: Fondo de Cultura Económica.

León, Dino y otros (eds.) (2011). Trabajos de historia, religión, cultura y política en el Perú, siglos XVII-XX. Lima: Fondo Editorial de la Universidad Nacional Mayor de San Marcos.

Lobo, Franco (2013). La construcción de las politicas industriales en el Perú, 1930-1939. Lima: Universidad Nacional Mayor de San Marcos. Tesis de licenciatura.

López de Azcona, Juan y otros (1992). Minería iberoamericana: Bibliografía minera iberoamericana, 1893-1992, volumen IV. Madrid: Instituto Tecnológico Geominero de España, Consejo Superior de colegios de ingenieros de minas de España.

Macera, Pablo (1966). Instrucciones para el manejo de las haciendas jesuitas del Perú (siglos XVII y XVIII). Nueva Corónica, II. Fasc. $2^{\circ}$.

Macera, Pablo (1968). Mapas coloniales de haciendas cuzqueñas. Lima: Seminario de Historia Rural Andina, Universidad Nacional Mayor de San Marcos.

Macera, Pablo (1972ª). Estadísticas históricas del Perú: Sector minero (Precios). Lima: Seminario de Historia Rural Andina, Universidad Nacional Mayor de San Marcos.

Macera, Pablo (1972b). Estadísticas históricas del Perú: Sector minero (Volumen y valor). Lima: Seminario de Historia Rural Andina, Universidad Nacional Mayor de San Marcos.

Macera, Pablo (1972c). Tierra y población en el Perú, siglos XVIII-XIX. Tomo I. Lima: Seminario de Historia Rural Andina, Universidad Nacional Mayor de San Marcos.

Macera, Pablo (1974). Las plantaciones azucareras en el Perú, 1821-1975. Biblioteca Andina. Lima: Seminario de Historia Rural Andina, Universidad Nacional Mayor de San Marcos.

Macera, Pablo (1977 ). Trabajos de historia. Tomo I. Lima: Instituto Nacional de Cultura.

Macera, Pablo (1977b). "Interpretative essay", en Cortés, Roberto y Stanley Stein (eds.). Latin America: a guide to economic history, 1830-1930. Los Angeles: University California Press. Macera, Pablo (1979). Conversaciones con Basadre. Lima: Mosca azul Editores.

Macera, Pablo (1992). Los precios del Perú: siglos XVI-XVII. Fuentes. Tomo I. Lima: Banco Central de Reserva del Perú.

Manrique, Nelson (1985). Colonialismo y pobreza campesina. Caylloma y el valle del Colca, siglos XVI-XX. Lima: DESCO.

Marczewski, Jean (1965). Introduction à l'histoire quantitative. Geneve: Librairie Droz.

Méndez, Cecilia (1987). "La otra historia del guano. Perú (1840-1879)". Revista Andina, 5, (1), pp. 7-81.

Menegus, Margarita (2000). El repartimiento forzoso de mercancías en México, Perú y Filipinas. México: Instituto de Investigaciones Dr. José María Luis Mora.

Mitchel, B.R. y Phyllis Deane (1962). Abstract of british historical statistics. Cambridge: Cambridge University Press.

Morner, Magnus (1979). Historia social latinoamericana: nuevos enfoques. Caracas: Universidad 
Católica Andrés Bello.

Pillsbury, Joanne (2008). Guide to documentary sources for Andean studies, 1530-1900, volume 1. Center for Advanced Study in the Visual Arts (U.S.). Oklahoma: University of Oklahoma Press.

Pinto, Honorio (1972). El primer censo agropecuario del Perú (1929). Lima: Seminario de historia Rural Andina, Universidad Nacional Mayor de San Marcos.

Pinto, Honorio (1973). Un sector exportador dependiente: La minería metálica en el Perú 19451970. Lima: Seminario de historia Rural Andina, Universidad Nacional Mayor de San Marcos.

Pinto, Honorio y Pablo Macera (1973). Estadísticas históricas del Perú, sector agrícola (Azúcar). Lima: Seminario de historia Rural Andina, Universidad Nacional Mayor de San Marcos.

Pinto, Honorio (1979). Contribución indígena en Bolivia, 1829-1911 (Documentos). Biblioteca Andina. Fuentes de Historia Social Americana, volumen V. Lima: Seminario de Historia Rural Andina, Universidad Nacional Mayor de San Marcos.

Portocarrero, Felipe (1974). "Encuesta en las ciencias sociales". Apuntes. Revista de Ciencias Sociales, 3, pp. 134-135.

Portocarrero, Felipe (2013). Grandes fortunas en el Perú: 1916-1960. Riqueza y filantropía en la élite económica. Lima: Universidad del Pacífico.

Portocarrero, Gonzalo (1982). "Reseña a Rosemary Thorp \& Geoffrey Bertram: Perú 1890- 1977 Growth and Policy in an Open Economy”. Debates en Sociología, 7, pp. 213-218.

Quiroz, Alfonso (2013). Historia de la corrupción en el Perú. Lima: Instituto de Estudios Peruanos / Instituto de Defensa Legal.

Quiroz, Francisco (1995). "La historiografía dependentista y el fin de la historia”. Nueva Síntesis, 3, pp. 138-148.

Ramírez, Luis (1980). Tribunal Mayor de Cuentas. Lima: Seminario de Historia Rural Andina, Universidad Nacional Mayor de San Marcos.

Ramos, Gabriela y Pedro Guibovich (1991). "La investigación sobre historia de los siglos XVI y XVII Perú, 1980-1990)”. Revista Andina, 9, (1), pp. 165- 237.

Romano, Ruggiero (1993). Coyunturas opuestas: la crisis del siglo XVII en Europa e Hispanoamérica. México: Colegio de México.

Salinas, Alejandro (2001). Estadística y contribuciones en el Perú. Siglo XIX. Lima: Seminario de Historia Rural Andina, Universidad Nacional Mayor de San Marcos.

Sarmiento, Jorge (2015). Implicancias de la Reforma Agraria en el campesinado y la desarticulación conflictiva de la cooperativa agraria de producción: El caso de Antapampa. Lima: Universidad Nacional Mayor de San Marcos. Tesis de licenciatura.

Seminario, Bruno (2015). El desarrollo de la economía peruana en la era moderna: precios, población, demanda y producción desde 1700. Lima: Universidad del Pacífico.

Soto, Clemente y otros (1977). Aproximación metodológica. Empobrecimiento absoluto y relativo. Paramonga. Lima: Seminario de Historia Rural Andina, Universidad Nacional Mayor de San Marcos.

Tamayo, José. “Panorama de los estudios históricos en El Perú contemporáneo, 1963-1994”. En: Tovar, Bernardo (comp.) (1994). La historia al final del milenio: ensayos de historiografía colombiana y latinoamericana, volumen 2. Bogotá: Universidad Nacional de Colombia.

Tandeter, Enrique (1983). Precios y producción Agraria. Potosí y Charcas en el siglo XVIII. Buenos Aires: CEDES. 
Tandeter, Enrique (1990). "Mercado y precios coloniales en los Andes". En: Boletín del Instituto de Historia Argentina y Americana "Dr. E. Ravignani”, tercera serie, 2, pp. 181-195.

Tantaleán, Javier (1979). Método y producción teórica en la historia económica. Lima: Seminario de Historia Rural Andina, Universidad Nacional Mayor de San Marcos.

Trelles, Efraín. "Historia económica colonial”. En: Bonilla, Heraclio (ed.) (1986). La crisis económica en la historia del Perú. Lima: Centro Latinoamericano de Historia Económica y Social.

Urrutia, Miguel y Mario Arrubla (1970). Compendio de estadísticas históricas de Colombia. Bogotá: Dirección de Divulgación Cultural, Universidad Nacional de Colombia.

Vásquez, Enrique (2000). Estrategias del poder. Grupos económicos en el Perú. Lima: Universidad del Pacífico. Centro de Investigación.

Walker, Charles (1989). "El estudio del campesinado en las ciencias sociales peruanas: avances, limitaciones y nuevas perspectivas”. Allpanchis, XXI , (33), pp. 165-205.

Zegarra, Luis Felipe (2011). "Línea de pobreza y salarios, 1913-1925: una primera aproximación”. Economía, 34, (67), pp. 39-56.

Fecha de recepción: 29/VIII/2016

Fecha de aceptación: 30/IX/2016 